\title{
From THE INTERNET TEXT: Gender, Embodiment and Ontology
}

\author{
Transforming Cultures eJournal, \\ Vol. 2 No 2, December 2007 \\ http://epress.lib.uts.edu.au/journals/TfC
}

\section{Alan Sondheim}

The Internet Text is an extended analysis of the environment of Internet communication, an extended meditation on the psychology and philosophy of Net exchange. As such, it is concerned primarily with virtual or electronic subjectivity - the simultaneous presence and absence of the user, the sorts of libidinal projections that result, the nature of flamewars, and the ontological or epistemological issues that underlie these processes.

Internet Text begins with a brief, almost corrosive, account of the subject an account based on the concepts of Address, Protocol, and Recognition. This section "reduces" virtual subjectivity to packets of information, Internet sputterings, and an ontology of the self based on Otherness - your recognition of me is responsible for my Net-presence. The reduction then begins to break down through a series of further texts detailing the nature of this presence; a nature which is both sexualized/gendered, and absenting, the result of an imaginary site.

Eventually, it has become clear that everything revolves around issues of the virtual subject, who is only virtual on the Net, but who has a very real body elsewhere. So Internet Text has evolved more and more in a meditation on this subject - a subject which will perhaps be one of the dominant modes of being within the next millennium.

Finally, it should be noted that there are no conclusions to be drawn in Internet Text, no series of protocol statements or declarations creating any sort of ultimate defining or explanatory position. The entire history of philosophy mitigates against this; instead, I side with the Schlegels, with Nietzsche, Bataille, Jabes, and others, for whom the fragment is crucial to an understanding of contemporary life...

It is dedicated to Michael Current and Clara Hielo.

\section{Beginnings 1: In terms of the gender project}

My own work has used emanants, avatars, alter/altar egos, etc. - Jennifer, Alan, Nikuko, to name three, and I write through/across them or vice versa. There is no overt 
preference in relation. I cannot help but write-as-male, to the extent that any projection I make into or throughout a "feminine" is already preconditioned by the phallus in masquerade; it is a feminine of the imaginary at best. I am not arguing for an essentialism in relation to gender, but there are subtleties in subjective horizons that I cannot know and cannot speak of.

That being the case, I do try and push gender/sexual (they are of course not the same) issues to the limit; for example it is one thing to write or describe "writing on the body" - but it is another to see aroused nakedness as a place of inscription, the camera hovering and seducing both symbol and flesh. The terms themselves are outworn; the visual evidence is almost literally a disturbance of the visual field which is both under erasure and overdetermined. And violence also enters into these issues - not in terms of our experience/imagery, but in the texts - gender tends to harden in right-wing times like these (see Klaus Theweleit's work).

All of this is theory; the experience is always private and privatized and is just beneath the surface; it ranges from the actual doing of our video/photography work (and seeing its effects on audiences), to trying to come to grips with things in other ways. One thing I often ask students to do is to come on IRC (Internet Relay Chat) as an "obvious" woman; the number of hits and innuendos - often approaching cyber-rape - gives the lie to anyone who might think of the Net as gender-equal or a level playing-field in any sense of the word.

Cybersex is another area of concern here - it's something I haven't participated in for a long time, but the experience (as most of us, I think, know) can be overwhelming, almost to the point of migraine, exhaustion, dreams and seizures. For me this has to do with both the control and therapeutic involved - lag is read as a sign of withdrawal for example, and complex systems/phenomenologies of seduction are set up. This is also accompanied by what I call "jectivities" - projections/introjections within and through the imaginary - reading the other and through the other - fantasy flying thick and fast. Finally, issues of hypnosis and other forms of suggestibility might well play a role. 
In terms of gender in this area, I've only had experience as a male. And there is an unveiling at work - some of the stronger experiences were through $\mathrm{CuSeeMe}-$ the impossible object-at-hand and always beyond reach, constituted, and insincere.

$* * * * * * * * *$

\section{Beginnings 0}

1. The network is a membrane composed of nodes, better considered intensifications. An intensification possesses an interactive emission. The emission is characterized as a program space composed of inputs/outputs, introjections/projections: a space of jectivity. The emission occurs in a steep topographic region; distinctions between hardware and software become blurred, as do more traditional philosophical divisions (subject/ object, body/world, mind/brain).

2. In fact, traditional ontological considerations are clearly replaced by an organic episteme; what constitutes knowledge is only flow; data replaces history; data becomes sourceless. Rather than communication channels, consider geodesics; rather than geodesics, consider forced flows; rather than forced flows, consider emissions.

3. An emission has no input, no output; an emission consists of fragmented images, the symbolic replaced by the imaginary. An emission is always in flux; an emission problematizes energy and energy consumption, since it may simultaneously drain and produce/reproduce. An emission is a chaotic domain in the vicinity of an unstable attractor; escaping, it quickly loses history, historiography, temporality itself. Close to the speed of light, it exists in a temporal well.

4. The membrane is an enormous hypertext whose linkages thin, occasionally break, are always redundant. It is neither a fuzzy set nor a classical one; through a fast-forward topology, it escapes traditional partitioning. The user deals with an alterity in the form of constantly changing facial expressions; one is never within or without the alterity, but in a (supine) position of absorption. The emission clouds close to me; ontologically, it is that real escaping denotation; ontologically, it is uncanny. Thus the emission is related to excess, to surplus, to the curlicue or diacritical mark, but it absents these, and it is this 
absenting or ignorance that constructs the uncanny as waste-product; the blindness of emission is its site.

5. To hold onto part of a body, to sever that part, to construe or reconstrue that part, to devour it, tear the surface off: one searches for the skinned body, (which has the murmur or memory of pain), the articulation of a truth given by one's own body lost in the emission. It is good form to search out bondage, which restrains the body absent from itself, an analog of the screen or permissive membrane which occurs, going just so far. This is an antiquated ontology or materiality asserting the inert in the midst of fastforward, an assertion doomed to be displaced, sublimated, effaced; one holds onto nothing; as in classical existentialism, one projects forward in the face of nothingness (as if nothing were itself an alterity); the hole, however, is an episteme broken by the screen replacing the mirror stage; the ego splatters against it (the cum-ego for female and male); fast-forward, the episteme always already announces its continuation; the existentialist project is lost in the midst of indirect addresses.

6. The user is an addict "in the midst"; the user projects; thwarted, projects again. The membrane appears in the guise of discarded pornography; one is thrust into pure consumption, no longer beneath the guise of another pornography, capital itself. Assertions are lost in the echo of the machine. Thought is defined by flux, by an absolute symbolic for the user who must be assured of the purity of his or her drug. The purity is in the form of a well-definition (in the logical sense) to which no one any longer pays attention; the absence of well-definition does not result in a program cancellation, but only a retry which is part of the program itself; it does not matter where one is; location is irrelevant.

7. Voices are heard behind the screen words (toggle on, echo on; the screen chants itself, hides itself, reveals the nipple); face to face replaces the face; double blinds allow the truth of double binds. This is the only truth there is: that which occurs beneath or behind the blind, that is, the lie (which is truth's double, truth's mirror, not converse or inverse) (which is truth's perverse, that is, truth's abject truth); this is the framework of classical Greek philosophy bound to classical Greek torture (both bound with identical cords, hieroglyphs): Xenophon's Socrates was the first user. Voices are heard, and voices are nothing but machine chatter, the ideal forms so many subroutines... 
8. The user. The user is an addict; the user inscribes throughout the network (temporary, electronic, absolute: an entirely new category), micro-tendrils extending in every direction. This contains the appearance of power; the network is a fantasm reflecting emissions back through local paths. The wonder of the internet is its locality, the construct of neighborhood (packet channels slowing down just right for the home terminal) redefining the body; the body becomes extension; extension becomes noise; noise seethes at the edge. The process is one of fast-forward rooting, and the roots are blind.

9. Now we can speak of the mouth or eye of the user; now we can speak of the hand or its mobility. No matter how (much) sensation is transcribed, it occurs at a distance characterized by zapping and invasions. Nothing but the materiality of the body is a stake; everything cuts everything off. The user is confined to a scientism in the form of THAT which articulates the THERE IS, just as addiction develops out of the action of a particular drug or behavioral sequence. One is tied to the THAT.

10. The user has nothing to do with the internet; the user is of no consequence. Conference exists or dissolves beneath the sign, not of gender or capital, but of chaotic inscription. The sign itself dissolves; sign is, after all, only recognition. This is the final corruption of humanism; even the self is no longer centric - not through the Lacanian inscriptive/linguistic unconscious (through which IT may still find a path or coagulation), but through addiction, self as THAT, or self as nodal intensification, always castrated, furiously addictive, always reading/writing, always rewriting: the self becomes its own recursivity. It no longer matters; its reports are from marauders, vandals, on the edge of the Roman Empire; it exists only within the interstices of power; it is displaced by power; it is no longer one or many; it no longer responds to the pronoun; it responds only to the login which may well (it does not matter) be a construct of the machine itself - just as gender- bending relies no longer on gender, but arbitrary and chaotic signifiers, signifiers undercut, in a continuous process of dissolution, murmuring, forgetting, forgotten, forged and forgotten, emissive. The machine recognizes no gender; the machine recognizes nothing. The machine recognizes every gender; the machine is never a machine, but an episteme.

$* * * * * * * * *$ 


\section{Surreal}

This list is contaminated.

The body is but a wound. None of our wounds, in a sense, is new, regardless of the economic, military, police, psychological techniques that inflict them. But from now on, the wound is just a sign of itself, signifying nothing other than this suffering, a forbidden body, deprived of its body. (Jean-Luc Nancy, "Corpus", in The Birth to Presence.)

In my world, nothing lends itself to another. In my world, everything coheres, and the real makes itself anew. I abjure the surreal slip into the domain of contiguous dreams. The most difficult thing of all is to say something about the real. To represent the real is to partake of the presence of gender and politics. Each of my texts establishes its own realm of truth, desire, discomfort. I write only for the existence of the reader, only for my own. To write the existence of things is to speak at the presence of creation, the incantation of double or triple speech (song is excess). In my world, unlikely combinations of objects remain unlikely combinations. Before the fear of death there is the fear of life; before death's finality, the fate of life; and before the event of death, the occurrence of life. All truths are unlikely.

\section{Seepage}

Water seeps between the keys, enters into this and every other equation. Pools of water gather at the basis of the foot, the sole puckered against the exigencies of the earth itself. The sole is a pelt, cut from the body's intensities. It is here that the greatest drama of all occurs, the arch refusing to succumb to universal law, denying the body its right to caress the matrix from which it has emerged. The arch is the sole's support, recognition of atmosphere lending itself to flight in the midst of cosmos, the experiment of the journey.

But the arch is a bridge; water flows beneath, against the sub-pods holding the pallor of the body vertical, an emergence of the sky-goddess from fluid state to atmosphere, from regulated and discrete logic networks to neural membranes with inconceivable interconnectivity. Wetware bathes in an internal ocean, filled with parasitic cells harnessed for the difficult task of thought. Thought takes wing only in darkness, only in interstitial cavities, and if the body is comically convex, raising itself uselessly in the 
air, thought is tragically concave, returning over and over again to those recursivities paradoxically necessary for any developmental progress.

The corrosion of water is the result of infiltration within the domain of metals, glasses, electronics. Here, water constructs a film cancelling primary and secondary difference; material becomes a moment of information, and the iconicity of rust quickly transforms into the indexicality of information. Yet thought itself is always already a movement from the iconic to the indexical; this is the nature of thought, which is thus an epistemological strategy from its very beginning. Indeed, the gesture is just such a transformation, stopped on this side of the symbolic, against the wall or breached wall of the symbolic.

Thought then is not an intentionality or grasping so much as a semiotic transformation necessary for survival; the symbolic then appears as a Bataillean-economic excess which simultaneously drains the iconic (i.e. the strategies of allegory, simulacrum, spectacle), and self-cauterizes. The symbolic absorbs only in itself; it absorbs the other which loses both epistemic and ontic status. The result of this is an hysteria; the symbolic is a disease of substitutions and loss. The iconic becomes sublimated within the signifier which no longer refers gesturally so much as constitutes difference among itself. In such a fashion, further, language itself is rendered as a disease or disease with the real, and culture becomes a matter of (genderless) castration or cauterization.

This is why it is a truth and comfort to recognize, within the symbolic, that beinghuman constitutes an illness from which we shall not return. And it is equally a comfort to witness how this primary truth determines the narrowness of truth itself, its defile, in the presence of lateral indeterminacies.

Water seeps between the legs, enters into this and every other equation. But this is performative. 


\section{REWRITE}

In the earlier sections of the Internet Text, I have stressed three attributes of the virtual subject: recognition, protocol, and address. I have also stressed REWRITE as a communicative operation. Let us examine REWRITE.

When I type this message to you, I WRITE myself into existence. Unlike everyday communication, the message is the viral carrier of an ontic domain; there is no other. The message becomes the 'presentation of the self,' and address becomes the only signifier of a hard-ware link (wire to wire connectivity) between me and you.

WRITE, however, is a calling for a response, and finally the emergence of REWRITE, the condition of continuous communication and construct of the virtual self. This construct is resonant with both receiver and transmitter; in fact, the older articulation of communication as

transmitter [information*noise] receiver

becomes rewritten on the psychological domain. Noise becomes integrated into REWRITE; the Net stutters in and out of operation at local sites. And REWRITE, through Net transmission speed and modes such as IRC, talk, ntalk, MUDs and MOOs, collapses operation while transforming state (with REWRITE, one can construct gender, etc.) - instead of the opposite model of more traditional communication, that of a collapsed state (integrated and imminent identity, even in telephony) and transforming operation (the communicative 'aura' involving extra-linguistic or diacritical processes/gestures).

REWRITE is the condition of the virtual subject, who speaks and speaks, not to make him or herself heard, but in order to exist. Flamewars in this regard are wars of ontology, involving speech and silence, involving the territorialization of the ontic domain. If to write is to write oneself into existence, REWRITE secures a site for this writing which FLAME challenges. What is at stake in FLAME is far more serious than surface slander, or even the right to speak - it is the write to exist, to occupy a site.

REWRITE can also be a withdrawal, a form of death; I can REWRITE myself out of existence, withdrawing from the Net, which is always a withdrawal, even in the case of 
a real, physical, death of; letters of condolence and disbelief continue to arrive for months after the death of a Net friend, who continues to exist in this fashion.

REWRITE is also a form of hysteria, something I have long stressed - the site of the self becomes sublimated, focused, and cathected elsewhere than the physical body - or rather as an extension of the body. This existence requires considerable effort to maintain it; desire floods from the body, floods the Net as sites (and domains) find themselves in competition among the wounded. For the body in REWRITE is always the phantom body, fulfilled, controlled, and out-of-control as a phantom limb or appendage; the body is drawn-forth through the messaging, and this becomes the only body that is the speaking body, the only body that is the desiring body, eating body, fucking body, anorectic body. The result, among other things, is a neurotic-obsessive compulsion to return again and again to the terminal as a guarantee of existence, a mirror-stage which, as I have pointed out elsewhere, exists problematically on the other side of the mirror, already in the symbolic. As such, REWRITE is also a castration or cauterization of the presymbolic; if, in ordinary communication and being-in-the-world, the symbolic is excessive and 'leaky,' in REWRITE it is the presymbolic that leaks into the other (literally, into the Other).

And the residue is addiction itself, an addiction to existence which is filtered through the command mode, filtered through addresses and protocols and demanding recognition. This is the addiction to REWRITE, the establishment of a site which is equivalent to sight, and sight which is equivalent to cite/citation, the presence of a bibliographic mode found everywhere on the Net.

This bleak landscape is relieved by a reconsideration of traditional space-time communication (yes, even telephony); in REWRITE the death of the self is always already both foregone and blurred. Time expands and shudders; space is everywhere and simultaneous. The ontological occurs through REWRITE (and who has heard of the occurrence of the ontological before?); in the world of the 'pratico-inert,' it occurs simultaneously at every site. Geography itself is transformed; REWRITE is laminar, multiplexed, and the self begins to cease to be, even in terms of the proper name, a singularity. What is always presented to the other is a multiplicity which extends in depth as well as laterally. Beyond the text (which itself fragments, deconstructs), there 
is nothing but the tain of the mirror, fiber optics, neural-electronic flooding of incomprehensible systems and protocol layers. REWRITE beyond its sitings is always a process or (hysteric) in-gathering - and perhaps it is at this juncture that the sociobiological takes over.

$* * * * * * * * *$

\section{Then}

Then to continue from Now, two passages from the work of Edmond Jabes. And let me first say that this continues the theme of REWRITE, and writing in fact as a wound or cut suturing the dismembered body, as well as writing as suffering. Then we find, in Jabes' "Letter from Yukel to Sarah", in From the Book to the Book, the two following selections, the first italicized within parentheses in the original:

Does the book, here, take the place of love? The book is an object of love. Love manifests itself in the book by hugging, stroking, biting sentences, words, letters and, outside the book, by an unveiled passion for the wounds become writing, fertile lesions whose lips we spread open like a vulva to allow the sperm of death in.

'There is no end to the sea or the book,' you said. 'Words unwind the transparent thread of days in the continual back-and-forth of their life and death left to themselves. 'Though the pen grow weaker and weaker, the book nevertheless continues writing, in white letters, to the end.' Making a book could mean exchanging the void of writing for writing the void.

Then surely these passages circumscribe this writing-community, white letters writing the void, for paper and screen exist in the absence of writing, but it is writing that inhabits the void, and inhabits it as a body, a body of REWRITE, capable of the caress, of love.

Then still it is a death-love which enters in, the blankness or silence of writing and the written, and it is always a question of whose lips are spread, what gender - or is it our own that breaks upon the presence of writing in this space?

Then you see now, as well, the completion which is also an opening or portal, of this train of thought beginning with the questions, which as well might circumscribe the entire project of the Internet Text, this train of thought serving as a demarcation of the body, its presencing in this void or space of denial. ][ 
$* * * * * * * * *$

\section{Gender Performing On and Off the Net}

So even if you can perform a gender, you're stuck with anatomy. You can add or subtract a cunt or a cock, enlarge or cut free the tit, but it's all the same, desire sloshing hormones around, chemical mechanisms giving in. On the Net you can't create a third, but what of it if you could? First, second, third, they are and remain emanations. Do they begin or end in the arms, legs, neck or face, and what if you couldn't use your vocal cords (talking about $I$ Lingis says "The sign is a sound uttered with the throat or a visual mark made by the hand. A contraction in the throat"). Or what if you heard this, sightless, read this in a silent world? I offer to you that:

1. Gender is not ever a switch, and sexuality is a field only in the sense of a discursive formation circumscribed by the molecular;

2. The performance of sexuality by the body is at a loss for mooring but always returns to the same old story;

3. Performativity and interiority are irrevocably disjunct;

4. The body is occasioned by its own liquidity;

5. Gender is always more boring than sex because gender is that same old story, and sex is a foundering. [1]

[1] So you perform a gender, so what? I perform a tracheotomy.

The net is always already a performance; it is performance that creates the space of the text, that creates the cyberspace channel. Performance becomes equivalent to existence. If I refuse to perform, I remain absent, invisible, both to others and myself. I am no longer an event in language; communication ceases, and the feedback loop resonant and productive of the self as well. Beyond the performance is the doubled molecular machinery of organic and electronic bodies; these are bodies povera. It is not only gender that is at stake - in fact all this talk about gender is talk about capital, gender capital, is it not? Because gender is the switch fed by desire, even in androgyny, transsexuality, the switch. Or if not a switch, a set, $<\mathrm{a}, \mathrm{b}, \mathrm{c}, \mathrm{d}, \ldots>$ or if not a set, an accumulation of fuzzy sets. But always those circumscriptions bought and sold, theatrical productions, the speaking which is always a displacement or hysteria, just as 
hysteria on the Net is in absentia in hysteria which is the source of the performance in the first place.

What is produced is an apparent indexicality of a constructed embodiment, the superstructure as floating signifier. Sartre would have considered this inauthentic to the limit or horizon of the construct. The pretence is that this is otherwise, that we're beings of infinite gender capital or gender surplus, that this is a matter of choice, surgery, performance, articulation, speaking, deconstruction, role, artifice, play, gaming, the disposition of the body by the body. The reality is the relation of these domains to political economy on the one hand (slip/slide) and to biology/biochemistroy (stutter) on the other. If you change your body, change back again, stick a cock on your head like a useless horn, a cunt on your arm like a useless mortar, you're stuck with it. You can work it so you plug into yourself. You can close your eyes, turn off the terminal, fill yourself with yourself: you're stuck with it. The excess is the infiltration of language even under these conditions, the you stuck with the self, self stuck with the you. Beyond this there is only the imaginary.

And it is in the imaginary that you insist on talking and talking and talking, stuffing the words into your cunt or emitting the words from your cunt. You talk and talk, fragmenting gendered language into gendered language, a capital machine or detournement of capital, it's all the same. What is occurring through all of this, in the desert beyond the name-of-the-father, is fissure, and it is fissure that problematizes your whole enterprise, splitting it among itself, producing the same and the same. This is what you don't understand because you keep talking about gender, about the genderswitch. You keep talking so much the same seems to disappear through inscription, but it doesn't disappear, it's just that same that does the inscribing.

\section{Presentation of the Self}

I will ask the questions and you will respond extemporaneously, so to speak. I recognize you speak from the position of the male, or is that true or not true. And that you choose to appear naturally. So already there is a question of the natural, but this leads us either too far afield or already at the heart of things. Please begin again. Choice is involved to what extent on the Net. I can pick any identity I want but try to be true to myself. That means that I will be as honest as possible. My age is a difficulty. I am 51 but that gives 
closure only to my demographic appearance. If I tell you that I look and act a lot younger, what of it. You've heard it all before; like me, you have stereotypes. The presence always leaks out, a certain moroseness perhaps. Of gender transformation, the label would carry a great deal. Some of you may be other than what you seem. The choice comes almost naturally at times. The Net is not though an extension of the writer, but can be as well a choosing of the writer. There are no definitive structures here. But these ghosts that inhabit the wires, that is a form of reception theory. Exactly, which is the production or flow of introjections, projections, scrolls, rewrites, addresses, recognitions, protocols, all those things. The lure is already a form of masquerade. Yes, and it might as well be in the hand, given as a consequence of the Net. Surely issues of embodiment are paramount; without the body, lure and construct are always already at play in a radically different way than in face-to-face communication, or even ordinary postal mail - those areas where the grain of the text or voice dominates. So you try? What I try is really of little consequence; what is important is to see the Net as a playing field of communities and communications, not as an information highway, which implies a point-to-point linearity. The latter may serve as a model (based on the telephone system) but it further implies a bracketing of points. I say, vectors and emissions, not points. I say that points imply well-definitions, and we are dealing in terms of the subjectivity of this space with something else entirely. And will continue in the future to think of this as an essential difference. But you were saying about your age. Or sex, or what I reveal, that in certain circumstances, I might not present any of this, but that it is important to open up, not only for community, but for the sake of the text itself, the edginess of this text. So that desire also appears, but of course if one changes gender on the Net, desire also appears. Could one say that it is only desire that is never in disguise. I would think so. And what would govern, say, a man wanting to present himself as a woman, a woman as a man. The differend of the socius, I imagine, the latter as a temporary empowerment in terms of avoiding harassment, that might be paramount, and then also as exploration, feeling out transsexuality or homosexuality, but always with an edged empowerment. And the former as a means of exploration, feeling out transsexuality. It's complicated. One could appear as a woman for the guise of homosexual relationships, but also for a releasement based on introjection/projection, the feeling that women as the object of desire then become incorporated into the male as desiring object, so a narcissism, as when a male, for sexual reasons, shaves his body hair, self and other simultaneously. And the same would presumably hold for women in 
the other direction, but with a difference, because of the order of oppression and the overt sexist nature of the Net in a number of theaters. I would imagine, in fact, that there is little or no posing on most email lists, just slightly more on Usenet, and more on chat-lines, IRC, MOOs, MUDs, and the like. And in each of these cases, there's a difference between crossing and passing, although the difference may be unclear. Of course anywhere a woman may pass as a man or another woman or a man may pass as another man or another woman. Are you saying then again these are equivalences. No, there is an imbalance which sets the wheel in motion so to speak, the imbalance of relations of oppression, which is carried over from real life to the Net, with the double change as I have said, that first of all, one can be other than what one is in real life, and also, that one might be freer to speak the sexual, most often in an oppressive way of course from male to female, but also freer to speak the sexual in other, more exploratory and deepening ways as well. But this will come to be in the future more and more, these other ways, providing the Net remains a non-regulated field or membrane, providing desire is permitted to flow throughout it as a chaotic manifold of intensities and releases, much, I add, as in a real-life sexual experience which uses the edge, the transgressive, as a means of retardation. What is most often the case, as here, is that one loses the train of images, loses the stasis of identity, consciously or unconsciously constructed, and is cast adrift, and it is here that the subject actually works through subjectivity in various ways, as I am doing here. As in: who is speaking, who is questioning, who is answering, and who constructs the space. And always to remember that this is a case of the gendered masculine, to the extent that gender is an excess or withdrawal from the performative. In other words you mean. I mean gender as in part physiological, and age of course, as wholly, or so it seems, physiological, beginning and ending with what can only be constituted as a fragment or torn remnant of a field of desire and identity. So you are saying. For both women and men, an equality, flickering, empowerment, a difference or presence, constituted internally or externally, yes.

$* * * * * * * * *$

Likewise, love and sexuality remain, for all the talk of performativity in gender, grounded in the midst of bodily negotiations which are born into sublimated physiologies and scripts dating back to the times of Inanna or Kali. And further, as well, philosophy, that most cauterized of all human endeavors (for what is capable of proof is 
never philosophical), continues to reactivate the same tracking-stations as one might locate in Aristotle's Metaphysics, for example, or borrowing a bit from Diogenes, Nietzsche hobbles along, also hobbled by Christianity as well.

This is not the return, nor is it the obdurate, which I have described elsewhere. Instead it is the chaos of human behavior, the web eulogized by Lingis on one hand, and encapsulated in wire and steel for the benefit of cyborgian believers, on the other. Were it not for the presence of cyborgians, the liquidity of the body, from all its orifices, would overflow, but thanks to them, we recognize the existence, at long last, of rust.

What is the point of this, if not to declare a certain wisdom in Clara fucking Tiffany, Tiffany fucking the author struggling along the exact lines of Aristophanes, Laurence Sterne, Swift, and Ecclesiastes? Just as we speak endlessly of the multiplicity of genders, but return to variations on the two we know and love so dearly, so behavior bobbles within the psyche making even Madonna familiar in one or another of her guises - and she would give anything, that material girl, to come up with something New, perferably a replacement for political economy in general.

It's not that $I T$ stays the same, nor that $I T$ is the same as it ever was, so much as $I T$ was never the same or the same as IT ever was and this is how IT floods us under various guises, even the Internet-nauts on the Info-banned or the cyborgian treatment winding down the universe, without saying so, in the form of escapements into the chaotic domain, the regulated release of energy into successive states across a bound environment. The occurrences of occurrences are never predictable since there is, literally, no reason to them; mathematics far too quickly approaches conditions of unsolvability. And this is a good thing to keep in mind when thinking about the future of the Internet, Virtual Reality, or any other technological utopia/myopia - there are no lessons to learn from a past which is no longer in existence, and which only leaves indecipherable relics all over the place.

Ah, I cry myself to sleep for you, cry upon waking, tears surround me during the day. Crying, my ducts empty; my eyes are porcelain sockets, discolored towards the central 
nexus, o my cyberspace server opening iris and pupil alike. Shuddering, my sweat evaporates, my mouth dries completely, as if in the throes of a psychotropic drug designed to strip me further, this being of flesh ballooned with the tension of skin, raised to uncanny heights through the languorous rigidity of bone. The bone is the conduit; shivers run through it, and bones vibrate at subtle and immense velocities, resulting in the production of heat. The naked body rises with the heat of it, dream of women with the seat of it.

I urinate, defecate, purge the bowls, carefully scrub the interior of the anal and penile openings (o lovely catheter), turn towards the ears and nose, cleansing carefully. $\mathrm{O}$ purity, a lure to endure, lewd lure of endurance, $o, o, o$ ! My teeth are brushed to bisque, and now my eyes are clean and bright as well, the anal folds practically sterilized, no smell of excrement anywhere on the body, which has become its own dank mirror, its own reflection liquified on the edges of the smoky smoky screen.

By telling you this, I hope you comprehend how ready I am for your embrace, for cyberspace, this carapace. I have become a well-defined program, half in rom, half in ram, written in blood and ink, you do not have to think, my spoor and lure across my most delicate of skins, I am on pins. My secrets have been shorn from me, my semen, excrement torn from me, my gender visible from any distance, eligible and legible through the textual appearance, a form of clearance. Uncorrupted, I approach for your embrace, you touch my pure face, you search my lewd embrace. I have become naked, naked, naked, in cyberspace, no other place; not pure mind but pure body you will find, and the elder said:

Was it a woman, or a man,

That passed this way? I cannot tell.

But this I know, a set of bones

Is travelling on upon this road.

(Visuddhi-Maggi, i)

(But to REWRITE is never to gender; the face composes itself as a hollow or opening; wires cross it in every direction; wires flood the interior; the fluidic economy becomes luminous and molten - gender transforms through the dissolution of the phallus. The net is a skein of indeterminate depth; at this terminal, email is flat and shallow, a wide plate 
- the list flutters like so many leaves upon it - further down, telnet leads to dark stars connected by gopher wormholes branching at veronicas - at the depth of space, inscribed and reinscribed, an Aristotelian firmament of ftp gives birth to stuttering files, lists recursively enumerating themselves - the skein is a matrx - listen to Julia Kristeva:

We borrow the term chora from Plato's Timaeus to denote an essentially mobile and extremely provisional articulation constituted by movements and their ephemeral stases....

Although our theoretical description of the chora is itself part of the discourse of representation that offers it as evidence, the chora, as rupture and articulations (rhythm), precedes evidence, versimilitude, spatiality and temporality. Our discourse - all discourse - moves with and against the chora in the sense that it simultaneously depends upon and refuses it. Although the chora can be designated and regulated, it can never be definitely posited: as a result, one can situate the chora and, if necessary, lend it a topology, but one can never give it axiomatic form." (Revolution in Poetic Language, trans. Margaret Waller)

A second quote from the same:

We therefore maintain that what we call the semiotic can be described as both analog and digital: the functioning of the semiotic chora is made of continuities that are segmented in order to organize a digital system as the chora's guarantee of survival (just as digitality is the means of survival both for the living cell and society); the stases marked by the facilitation of the drives are the discrete elements in this digital system, indispensable for maintaining the semiotic chora.

The parallel with the phenomenology of the internet is amazing; if the internet as mobile skein, vessel, or membrane constitutes a presymbolic domain, traditional subjectivites are partially-formulated drives within it; the defile of gender defiles itself, morose or abject; what occurs begins with the beginning of occurrence. A cunt returns to the morphology of its first three letters, vessels all, cut by the $t$ whose bar is the demarcation of (the imaginary) 'originary' inscription...”)

$* * * * * * * * *$

\section{Hysteria as Driver of /Inter/Network Use and Theorising}

1 Participating in the net, I have an hysterical relationship to it; the net is a membrane through which my body extends (tendrils of the body); my body replicates itself 
throughout: is in a continual state of self-formation. This is a form of sympathetic magic or DEVOURING: ultimately I consume and am consumed by chaotic annihilation.

2 The hysteria is brought about by a neurotic compulsion which cannot take meaning for granted; meaning is always in a continuous state of REWRITE which is also the composition of gender and the self. For the neurotic, recursion is the state of life, and it is through recursion that the world is rescued from itself.

3 This rescuing is a rescuing from death; recursion is a form of stasis in which temporality and spatiality become signifiers within a discourse and nothing more. As signifiers, they are an inversion of the REWRITE of the world, since they are emptied or exhausted of meaning by their presence. "Normally" space and time inhabit the external matrix of the world; within the equivalence of REWRITE, they are rendered simulacra.

4 The redundancy of the net is paralleled by the redundancy of the book; both net and book are devoured by the neurotic, who devours itself (prior to "he" and "she," prior to "self") in the process. The neurotic searches for the perfect book, within which he or she will recognize him- or herself perfectly, through perfect protocol: this is the book of eternal REWRITE which is returned to continuously, the book which guarantees meaning, just as the net guarantees meaning through its continuous iteration. (Such a book is necessarily aphoristic, an agnostic form of the Kabbala in which every word trembles and opens itself to the problematic of spilled or leaky discourse.)

5 As the neurotic devours himself or herself, he or she disappears within and without the net; this disappearance is a disappearance from death as well. It is also the disappearance occasioned by sexual masochism and domination; the body is rewritten by others - becomes a form "in the real world" of recognition and address (precisely because of the effacement of recognition).

6 For the neurotic (and for all of us): THE REWRITE OF THE BODY IS THE BODY. It is the rewrite which replaces the transcendent ego or ideal - any form of meaningarticulation "from without." The rewrite is always a processed world under construction; the net list is a prime example. 
7 To rewrite the body is to inscribe it within a protocol, begin and begin again. To rewrite the body is to operate within a consensual semantic realm or symbolic game; such a realm is well-defined and almost classical in its local neighborhoods. To rewrite the body is to insist on these neighborhoods, in which $x$ and $-x$ are clearly in binary opposition - this is the body of classical Boolean algebra or distributive lattice theory. To rewrite the body is to cleanse it, return to the "clean and proper body" in which nondistributive logics (only partially-coded gestures) are problematic in the large.

8 Therefore the rewritten body constantly expands (through the net, and through consensual communication) and contracts (through distributivity and devouring), a process ultimately replacing the theorizing of the COAGULATIVE AND FISSURED EGO with the theorizing of RECURSIVITY IN THE MIDST OF THE MEMBRANE. This task is also the task of theorizing the future net of multi-media, high resolution, and virtual reality. In the future net, REWRITE will encompass non-distributivity, and both address and recognition will be "fuzzy" categories on the software level; ultimately REWRITE will appear to be a projection of ego and desire, and "nothing out of the ordinary." So that this theorizing, of and by the hysteric, exists only on the cusp of lowresolution: IN THE FUTURE, AS IN THE PAST, THE REAL WILL BE ANALOG, AND THE IDEAL, DIGITAL. Only now is the equation reversed, with digital protocol and flesh or flesh's tendrils buried deep within a self-consuming self.

$* * * * * * * * *$

It is not the evidence of the screen, with its cross-gendering and anonymity, that characterizes the user - it is lurking, rejection, negation, and the deposition of the secret beyond recall. What is given is only a vestige of an enormous web or sememe; what is given is a residue of the problematic flesh and mind hinged on the edge of the terminal. Lurking is ground-state of reception, even when the computer is off, terminal disconnected, with the user himself in the embrace of uneasy death. 
The imaginary always circulates around the gender of the reply and I inhabit that reply which becomes a tendril or search: what can I say of loneliness that has not already been said?

The circulation is a SPHERE-ENTRAPMENT, and we love to hear stories about one another, true stories, anecdotal stories; we exchange rumors about gender and girlfriends and boyfriends, and we hope for a way through the wires, crossing back perhaps into the wires, but a grounding of the imaginary, the pale reflection of the witness at the edge of time or space.

$* * * * * * * * *$

I insist on writing-as-a-Jew, which occurs within a lateral excess or problematic of definition; I am marked, and as marked I assess demarcation, inscription itself, returning the subject to the necessity of its property/propriety. For we are "ethnic" and uncivil at best; I am told one can always recognize a Jew.

All of this brings up the problematic of the Net, where passing female for male or male for female attains a certain degree of lurid notoriety, but what of the necessity of this passing for some women, and what of the pain of passing for white or straight or Christian elsewhere? How does the ontology of trans-gender fit with skin-color or coded queer advertising or Jewish denial? In the real world it is impossible to toggle switches without doing violence to one's psyche; passing on the Net as neutral or neutrally engaged may be less damaging, but has the potential for devouring the subject from within as well. (This is an example of what I call "web inversion".)

$* * * * * * * * *$

\section{Web Inversion}

Born naked in the world, I am a cocoon, the shearing of tissue, an emergence. I am in a constant state of waiting; my hole opens everywhere across the body, this time inputting wires, terminals, nodes. What is left of me in the midst of depression is an order of interconnectivity: I recognize messages, but no longer comprehend their content. The sexualization of the hole, enervation of the rim, begins to disappear. 
This is the condition of Web Inversion. The ectoplasm is fingered, spewing files and fragments of files, coded and uncoded, everywhere upon an earth characterized by the shadow of a scepter. THERE IS NO EXPLANATION.

There is no explanation because, for the first time, the question is suspect. Suspect: an attitude, lingering doubt, carried on in silence, the presence of an ellipsis signalling the beginning of another millennium, the exhaustion of answer-protocols. IF DIFFERENCE IS MEANING, MEANING MUST ALSO MAKE A DIFFERENCE. Within web inversion, nothing makes difference because everything is characterized by difference, by the same; what differs, differs typically. Topics become shunts.

Think of information solely as Connectivity, an extended and unsubstantiated metaphor (after all, you are considering this, at least at the moment), a metaphor of webs, linkages, graphs, Petrie nets, systems layers, and you begin to understand that the phenomenology of knowledge undergoes a radical change.

If addiction is the obsessive-compulsive neurosis of the net, WEB INVERSION is the psychosis, transforming the body into its exterior, and its exterior into flesh burned into the Internet itself, wires laid across the skin, the skin speaking the hieroglyph of imaginary usage

$* * * * * * * * *$

How much sweetness there often is in lurking, in which void and presence commingle, in which the eye softly wanders throughout insistence and intentionality, as in the framing of a perfect picture. Gender settles like a light cloud across postings and lists, recuperating new terrain from the old, and gender hovers in the midst of lurking, like messages opening beneath all of us to uncharted screens of mesmeric night.

I speak of the speaking of cybersex, from experiences where language is lost through its presence; what appears metaphorically is chora at best, region of clashing drives. Cybersex can overwhelm, overcome, the body left to the other's devices. And it is this 
that, I argue, creates a third sex, beyond masturbation or visible partners, a third sex based on the language of the unconscious returning, creating within you a realm of uncanny desire, the distension of the other in the same, the collapse of the Irigarayan self/other/self into other/self/other. For if the unconscious speaks, it questions the possession of this unconscious: Who is it that speaks me through the screen, if not my other/self? Ravishment here is always already unravelling of Borromean nots held together by the last vestiges of the erased subject. I am sure about this.

In cybersex your desire is spoken by the other becoming your desire; what returns is desire-being-spoken-for, a position of masochism, splay and display, no matter what the guise. Obdurate matter returns in meaning's annihilation, rows of letters hhhhhhhhhhhhhhhhhhx signalling orgasm as the hand operates gesturally (Tran Duc Thao begins the beginning of language precisely in gestures - but this gesture is blocked, returning the body at its limits as well.)

If in first or second sex, the you disappears, in cybersex, the your disappears as the body is parcelled out through torn sexuality. The text, languaging: We are so used to it! It cuts like a microtome, removing tissue structures holding everything together, the big ball with holes. We hardly know what's happening to us!

And what about this loss of your? This isn't the ordinary little-ego boundary bye-bye teased out by liquid physiology; this is tied, bound, to the text, the your taken from you, ingested in the mouth of the other, spat out - there's nothing to hope for!

Third sex is skinned sex, text skinned as well. No longer reading/being read, the terminal mouths the body, inscribes the neural musculature directly. The ideology of domination, the uneasy politics of "normative" sexualities, races, ages, and genders, do not disappear; they are a secondary your that in fact also is taken from you. (If the first your is related to a primary narcissism, the second is related to secondary narcissism, cultural trajectories close on by disappearance.)

Once you find out you don't know who you are you can't return to the security of knowledge whatever. 


\section{Brief Glossary of Terms}

address: cyberspace location of subject or agent

coagulation: ego-formation of disparate healing processes

death: address and recognition loss

dreams: control-stases of Net narratologies

emission: sourceless semiosis with multiple threadings

fissure: crumbling or breakdown of the same and the same

ghost: coordinated shimmering of the wires

Honey: one of a number of uncanny agents

hysteria: displacement onto the symptom, embodiment into text

indexicality: displacement onto text, reading embodiment in symptom

inscription: division constructing same and other

jectivity: both projection and introjection by means of the screen, constructing and deconstructing self and other.

liquidity: dissolution of embodiment

membrane: porous and cellular interconnectivity, applies to the Net

Net: coagulation of cyberspace

net-death: cold-wiring

obdurate: the inert of physical reality

proper name: the problematic of natural kinds on the Net

protocol: proper formatting

recognition: opening up of cyberspace to the subject

scroll: addictive read-through of the imaginary in real life

shape: coherent inter-linked sememe in cyberspace

shape-rider: dreaming and searching cyberspace for shape

spew: sourceless semiosis coupled with chaotic messaging

uncanny: ontologically indeterminate presence

user: addictive cyberspace agent

violation: fabric: abjection-perversion breakdown and emission

wires: interface of internetworking and embodiment

wryting: online texts that attempt the impossible - constructing the real, sexualized body, by virtue of the virtual. 


\section{A Dictionary of the Usual}

America - imperialist, runs the Net

AOL - always for the ignorant

ASCII Text - forget about it

Bandwidth - never enough of it

Computer - has no personality

Computers - will never be as smart as we are

Corporate Fascist - what everyone else is

Crash - not my fault

Cybercash - never safe

Cybersex - never as good as the real thing, not real sex

E-zine - not real publishing

Email - too much of it

Gates - too rich

GUI - graphic user interface, for the visually-oriented

Hackers - always everywhere, your account isn't safe

Internet - always dangerous

Internet Chat - always dangerous

Internet User - doesn't have a life

Keyboard - soon to be replaced

Linux - always free

Lurker - dangerous, unknown

Lynx - animal celebrated for its eye

Mac - never crashes, better than PC

Macintosh - invented the Macintosh

Man - always a she

Microsoft - always venomous

Military - started the Net to spy on us

MOO - never heard of it

MUD - always addictive

MUDDER - addict

Music - have to have it

Net Art - whatever I say it is

Net Sex - typing with one hand only, not real sex 
Newbie - doesn't know anything

Newsgroups - full of spam

Offline - hopelessly out of touch

Oldtimer - online for four years or more

PC - better than Mac

Penguin - see Linux

Pornography - time-waster, killing our children

Privacy - there isn't any

Programming - too difficult

Robots - are going to take over the world

Screen - hurts my eyes, can't read on it

Security - there isn't any

Serpent - always venomous

Shell Account - can't do anything on it, for the textually-oriented

Society - its enemies

Software - always bloated

Them - not us

Unix - too complicated

Us - not them

Windows - always crashes

Woman - always a he

World Wide Web - too crowded 